\title{
Betterness of permissibility
}

\author{
Benjamin Ferguson ${ }^{1}$ (D) Sebastian Köhler ${ }^{2}$
}

\begin{abstract}
It is often assumed that morally permissible acts are morally better than impermissible acts. We call this claim Betterness of Permissibility. Yet, we show that some striking counterexamples show that the claim's truth cannot be taken for granted. Furthermore, even if Betterness of Permissibility is true, it is unclear why. Apart from appeals to its intuitive plausibility, no arguments in favour of the condition exist. We fill this lacuna by identifying two fundamental conditions that jointly entail betterness of permissibility: 'reasons monotonicity of permissibility' and the 'weak classical view'. We then argue that there are good reasons for accepting both of the fundamental conditions. We note that there exist plausible moral theories that reject one of the fundamental conditions. However, the way in which those theories reject the fundamental conditions does not allow them to endorse the counterexamples that motivate the belief that Betterness of Permissibility might be false.
\end{abstract}

Keywords Permissibility $\cdot$ Reasons $\cdot$ Goodness $\cdot$ Bridge principle $\cdot$ Conditional Obligations

$\triangle$ Benjamin Ferguson

b.r.ferguson@vu.nl;

http://benjaminferguson.org/

Sebastian Köhler

skoehler@fs.de;

http://sekoehler.weebly.com/

1 Department of Philosophy, VU Amsterdam, 1105 De Boelelaan, 1081 HV Amsterdam, The Netherlands

2 Philosophy \& Law Department, Frankfurt School of Finance \& Management, Adickesallee 32-34, 60322 Frankfurt, Germany 


\section{Introduction}

Suppose that as you stroll along a beach one evening a storm suddenly strikes. You soon hear the panicked shouts of two swimmers who will surely not last long in the growing swells. Though you'd like to help them, you're no seaman and the conditions are extremely perilous; if you put out to save them, it is possible you'll all drown. We think most people would agree that, given the risk, you are not morally obliged to save the swimmers. However, it also seems that if you could save even one, this would be morally better than staying on the beach. Nevertheless, suppose that you spot a dinghy on the beach and heroically attempt a rescue. When you reach them, the swimmers are side-by-side and you could pull both into the boat and make it back to shore. However, suppose you save only one, leaving the other to drown. We think most people would agree that if you do put out to save the swimmers, given that you could save both, it is impermissible to save only one. ${ }^{1}$

If you believe it is not obligatory to attempt a rescue, morally better to save one than none, but impermissible to save only one, then you are committed to the claim that there are situations in which impermissible acts are morally better than permissible acts. This claim conflicts with the common moral platitude that Permissible acts are morally better than impermissible acts. Call this claim betterness of permissibility, or BOP.

Determining what one ought (and ought not) to do in situations like the drowning case is an important issue. However, the point of this paper is not to argue for a particular verdict in such cases. Rather, we will show that verdicts about what one should do that are incompatible with воР incur a high theoretical cost. In particular, verdicts which claim both that it is morally better to save one than none and that it is impermissible to save one violate воР. We will show that accepting such verdicts requires abandoning at least one of two widely held views about the relationship between reasons, actions, and goodness.

If you think вOP is obviously true, you might set out to debunk the moral assessments in the drowning case that jointly contradict it. However, it is unclear what considerations, apart from intuition, support воР because even though it is commonly accepted, it is nowhere explicitly defended. ${ }^{2}$ So, you could instead take these intuitions about the cases at face value and reject the platitude. After all, there is no necessary logical connection between permissibility and moral goodness. ${ }^{3}$ In short, if the воР platitude is true, it is unclear why.

\footnotetext{
${ }^{1}$ Let us also suppose that there are no antecedent moral obligations that prohibit you from attempting to save the swimmers and that neither swimmer is morally more deserving of rescue.

2 Sobel (2013: 102) endorses the condition, but he implies that it is obviously true, writing that "It is not merely that the morally permissible acts are better than the impermissible. Some bad types of action are worse than others."

3 There is, of course, a connection between goodness and permissibility within particular moral theories. Consequentialism, for example, defines permissibility by way of goodness. But the defence of these relations requires additional argument. BOP is a metaethical claim about moral goodness in the sense in which consequentialists and non-consequentialists offer competing theories of what it is. It is a claim that constrains the possible relations between goodness and permissibility that might be advanced at the level of normative ethics.
} 
Our primary aim in this paper is to identify theoretical claims that could be used to support or criticise вор that go beyond mere platitudes. In Sect. 2 we identify two antecedent claims and show they jointly entail вор. In Sect. 3 we identify a number of cases that, like the drowning case, elicit intuitions that conflict with BOP. The breadth of these cases demonstrates the urgency of assessing the truth of the antecedent claims. In Sects. 4 and 5 we consider the plausibility of the two entailing conditions. There we show that BOP violating judgements in counterexample cases come with a very significant—and as yet unrecognised—-theoretical cost. Section 6 concludes.

\section{The formal framework and entailment claim}

If вOP is true, it should be supported by theoretical arguments. Yet, as we noted above, no argument for BOP currently exists in the literature. In this section we identify two conditions that jointly entail воP. These conditions not only provide antecedent support for BOP, they also help to clarify how moral reasons, moral value, and moral permissibility are related.

Here we present a formal framework in which воР and the conditions that entail it can be more precisely expressed. First we define вор in this framework, then we present the two conditions: the weak classical view and reasons monotonicity of permissibility. Finally, we provide an informal proof of the entailment claim and discuss an objection to our formal assumptions.

\subsection{Defining BOP}

We will assume that moral goodness and permissibility each retain a basic structure that is independent from both the content that they are given by any particular moral theory and the way that any particular moral theory relates the two (e.g., whether that theory respects воP). Thus, we appeal to the broad concepts of permissibility and goodness and not to particular conceptions of goodness and permissibility found within particular moral theories.

We will be concerned primarily with moral goodness as a property of acts and do not follow the more common restriction of goodness to states of affairs. Admittedly, this is already a significant assumption, since it conflicts with the standard consequentialist claim that moral goodness is a property of states of affairs. ${ }^{4}$ By focusing on the goodness of acts, we do not deny that states of affairs can also be good. And indeed, we think consequentialists can easily endorse BOP. Consequentialism is compatible with воР if acts' goodness derives from, or is grounded by, the fundamental (for consequentialists) goodness of state of affairs. That is, consequentialists could allow that acts are good just in case they have an appropriate

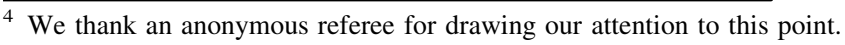


promotional relation (e.g. actual promotion, expected promotion, etc) with this fundamental source of goodness. ${ }^{5}$ We turn now to the formal framework.

Let $X$ be a finite set of (token) acts, $Z$ be the set of all nonempty subsets of $X$, and $A$ be an agenda ${ }^{6}$, such that $A \in Z$. We define moral goodness in terms of betterness relations. Let $\succcurlyeq_{m}$ represent weak moral betterness, a relation defined on $X$, such that $\forall x, y \in X: x \succcurlyeq_{m} y$ iff $x$ is morally at least as good as $y{ }^{7}$ We assume $\succcurlyeq_{m}$ is a total order on $X$; that is, all acts in $X$ can be ordered on a 'goodness scale' where higher ranked acts are morally better, or 'more good', than lower ranked acts. ${ }^{8}$ We presuppose no link between prudential and moral goodness. Moral goodness need not be restricted to what is 'good for' a person. Further, our understanding of goodness is compatible with buck passing accounts of goodness that claim goodness "is not a property that itself provides a reason to respond to a thing in certain ways, [but] to be good or valuable is to have other properties that constitute such reasons" Scanlon (1998: 97).

We will assume that permissibility is a modal property that partitions acts into two mutually exclusive categories: acts are permissible iff they possess some rightmaking property and acts are impermissible iff they are not permissible. ${ }^{9}$ Note that what we mean here is permissibility and impermissibility all things considered, not prima facie. We let $\mathrm{P}$ represent permissibility and $\neg \mathrm{P}$ impermissibility. It is now possible to formally define вОР as the claim that for all agendas $A$ in $Z$ and all acts $x, y$ in $A$, if $x$ is permissible and $y$ is impermissible, then $x$ is morally better than $y$ :

$$
\forall A \in Z, \forall x, y \in A: \quad(\mathrm{P} x \wedge \neg \mathrm{P} y) \rightarrow x \succ_{m} y
$$

Having formally defined воР, we now turn to the two conditions that jointly entail it.

\subsection{The weak classical view}

The weak classical view is a weakened version of the the classical view of intentional action, a widely held (Anscombe 1957; Aristotle 1999; Davidson 1963; Raz 1999; Smith 2009) account that claims "intentional action is action for a

\footnotetext{
5 Some consequentialists may deny that there is any sense in which goodness can be a property of acts. For those theorists, BOP, in both its formal and colloquial forms, involves a category mistake. We do not claim that BOP must be true of all moral theories. Rather we claim that theories with language rich enough to express BOP have good reasons to respect it.

${ }^{6}$ An agenda is is simply the set of options available to an agent in a particular context. We use agendas here since acts' permissibility and goodness may be relative to the options available to an agent. If A can only save B from death by breaking her arm, then doing so is permissible. But it is not permissible if less harmful options are available.

7 We define moral indifference and strict moral betterness in the usual way: $\forall x, y \in X: x \sim_{m} y$ iff $x \succcurlyeq_{m} y$ and $y \succcurlyeq_{m} x$; and $\forall x, y \in X: x \succ_{m} \quad y$ iff $x \succcurlyeq_{m} y$ and $\neg\left(y \succcurlyeq_{m} x\right)$.

${ }^{8}$ The total order assumption implies betterness relations over actions are complete and transitive. Weak moral betterness is transitive when, $\forall x, y, z \in X$ : if $x \succcurlyeq_{m} y$ and $y \succcurlyeq_{m} z$ then $x \succcurlyeq_{m} z$. Transitivity is criticised in Temkin (2012), though see Voorhoeve (2013) for a rebuttal. Weak moral betterness is complete when $\forall x, y \in X$ where $x \neq y: x \succcurlyeq_{m} y$ or $y \succcurlyeq_{m} x$ or $x \sim_{m} y$. Vallentyne (1993) challenges the completeness assumption, which we discuss below.

${ }^{9}$ For theories that make permissibility a function of multiple properties, acts are permissible iff rightmaking properties are undefeated. Peterson (2013) defends an alternative approach.
} 
reason; and that reasons are facts in virtue of which those actions are good in some respect and to some degree" (Raz 1999: 23). The weak classical view departs from this traditional view in two ways. First, it concerns only the second half of the traditional view. The weak version makes a claim only about the relation between reasons and goodness. Second, the weak classical view is restricted to the moral domain and concerns only moral reasons and moral goodness.

Let $\succcurlyeq_{r}$ represent 'weak reasons superiority', a relation defined on $X$, such that $\forall x, y \in X: x \succcurlyeq_{r} y$ iff the moral reasons that speak in favour of performing $x$ are at least as strong as the moral reasons that speak in favour of performing $y .{ }^{10}$ Formally, the weak classical view claims that for all $x$ and $y$, there is at least as strong a moral reason to $x$ as there is to $y$, if and only if $x$ is at least morally as good as $y^{11}$ :

$$
\forall x, y \in X: \quad x \succcurlyeq_{r} y \leftrightarrow x \succcurlyeq_{m} y
$$

\subsection{Reasons monotonicity of permissibility}

The second condition, reasons monotonicity of permissibility concerns the relationship between reasons and permissibility. The condition claims that if act $x$ is permissible, then any other acts that the moral reasons speak more strongly in favour of performing must also be permissible. Note that the condition does not require maximisation. It does not claim, (as Davidson's continence principle does) that we ought to "perform the action judged best on the basis of all available relevant reasons" (Davidson 1980: 43). It merely entails that all acts that are at least as strongly supported as the permissible act with the weakest reasons must also be permissible.

Formally, the condition claims that for all agendas $A$ in $Z$ and all acts $x, y$, in $A$ if $x$ is permissible and the moral reasons for performing $y$ are at least as strong as those for performing $x$, then $y$ is also permissible. That is,

$$
\forall A \in Z, \forall x, y \in A: \quad\left(\mathrm{P} x \wedge\left(y \succcurlyeq_{r} x\right)\right) \rightarrow \mathrm{P} y
$$

\subsection{Entailment}

In "Appendix 1" we provide a formal proof that the weak classical view (2) and reasons monotonicity of permissibility (3) jointly entail BOP (1). Informally, however, the relationship between the claims is fairly straightforward. At the general level, reasons monotonicity is a claim about how the moral reasons for an act relate to its permissibility. BOP is a claim about how the moral goodness of an act relates to its permissibility. To move from one of these claims to the other we require the weak classical view, which claims that moral goodness is a necessary condition for moral reasons.

More precisely, if it is true both (by (3)) that if act $x$ is permissible, then any other acts that the moral reasons speak more strongly in favour of performing than $x$ must

\footnotetext{
${ }^{10}$ We define reasons equivalence and strict reasons superiority in the usual way: $\forall x, y \in X: x \sim r y$ iff $x \succcurlyeq_{r} y$ and $y \succcurlyeq_{r} x$; and $\forall x, y \in X: x \succ_{r} \quad y$ iff $x \succcurlyeq_{r} y$ and $\neg\left(y \succcurlyeq_{r} x\right)$.

11 Note that since we assume $\succcurlyeq_{m}$ is a total order on $X$, by (2), it follows that $\succcurlyeq_{r}$ is too.
} 
also be permissible; and (by (2)) that if there are stronger moral reasons for $x$ than $y$, then $x$ is morally better than $y$; then (1) also follows: all acts morally better than $x$ are also permissible. Thus, as BOP claims, there can be no impermissible acts that are morally better than permissible acts.

These two conditions do not constitute a full theoretical argument for BOP. We provide this discussion in Sects. 4 and 5. However, we point out that on its own, this entailment does provide an antecedent consideration that speaks in favour of вOP because arguements about the plausibility of вор can appeal to these more fundamental claims, rather than relying on intuitions about cases and moral platitudes.

\subsection{Completeness}

Finally, we will briefly discuss an objection to our assumption that $\succcurlyeq_{m}$ is a total order on $X$. This assumption implies moral goodness is a complete order. There are many ways completeness can be violated. For example, acts might be incomparable in terms of betterness because they are "on a par" (Chang 1997, 2002) or "roughly equal" (Griffin 1986) and acts might not be comparable at all, because their values are incommensurable (Raz 1986). Many moral theories allow value incommensurability or incomparability and thus, do not satisfy completeness (Vallentyne 1993). Incompleteness is often motivated by dilemmas, such as 'Sophie's choice' (Styron 1980) which forces a mother to choose which of her two children to sacrifice, 'Sartre's choice' which involves selecting possible futures (?), and 'hard choices', e.g., between careers (Raz 1986; Chang 1997).

However, to our knowledge all illustrations of incompleteness rely on the incomparability of two permissible acts or two impermissible acts. These cases do not directly threaten BOP, which compares permissible acts and impermissible acts. Perhaps certain comparisons within the domain of permissibility or within the domain of impermissibility are not possible. But as long as we can compare permissible acts to impermissible acts in terms of moral betterness, incompleteness does not threaten воР. Furthermore, none of the counterexamples to BOP that we will illustrate in the following section rely on incompleteness. Those cases all involve explicit betterness comparisons. They threaten воP not because the moral value of the acts they involve cannot be compared in terms of betterness, but rather because they involve assessments that contradict BOP.

\section{BOP violations}

The previous section demonstrates that the weak classical view and reasons monotonicity of permissibility jointly entail BOP. This result is important because it connects BOP, which is a metaethical claim, to two claims about rational action. These more fundamental conditions help us to better understand why вOP seems so plausible. Yet, without further argument, they do not definitively tell against the BOP-violating intuitions in the drowning case. We will assess the plausibility of the weak classical view and reasons monotonicity in Sect. 4 and 5. First though, in this 
section, we present three other cases that elicit BOP-violating intuitions. In all of these cases there are various ways that the moral verdicts can be made compatible with вор. However, as in the drowning case, we will not defend any particular constellation of BOP respecting judgements. Our purpose in this section is to demonstrate that BOP constrains moral judgements in a much broader range of cases than the drowning example. This broad scope of applicability makes the assessment of the entailing conditions' truth all the more pressing.

\subsection{Exploitation and conditional obligations}

The first case involves exploitation and unfair transaction. It is structurally is similar to the drowning case. As Ferguson (2016) shows, the following three claims are commonly endorsed ${ }^{12}$ in debates about exploitation and they jointly imply that вOP is false. It is:

(E1) Permissible to not engage in mutually beneficial transactions, but

(E2) Morally better to engage in mutually beneficial transactions than to not,

(E3) Impermissible to gain unfairly in mutually beneficial transactions.

вOP is violated when a transaction is mutually beneficial, but unfair because by (E3) engaging in it is impermissible, but by (E2) morally better than not transacting and not transacting, by (E1) is permissible. Although engaging in mutually beneficial transaction is not ordinarily morally required, if you choose to engage in a mutually beneficial transaction with someone, then, it seems, you're obliged to do so fairly. Although Ferguson himself rejects the welfarist claim (E2), David Faraci has recently argued that BOP should be rejected instead. He claims "there are perfectly consistent, intuitive ethical positions that vindicate [claims (E1-E3)], in particular "deontological claims on which more rightness goes hand-in-hand with less goodness" (Faraci 2019: 170, 175).

Both the exploitation case and the drowning case ${ }^{13}$ are a token examples of a case type that involves the conjunction of the following three claims. It is:

(C1) Morally permissible to refrain from performing acts of type $\Phi$, but

(C2) Morally better to perform acts of type $\Phi$ than not, and

(C3) Some token $\phi$-ings are impermissible.

This last claim, (C3), relies on a form of conditional obligations (Pummer 2019; Horton 2017) that arise only after a person commits to a particular action type, such as the conditional claim that 'if you put out to save the swimmers and can easily

\footnotetext{
12 See Zwolinski (2007) and Wertheimer (1996) for discussions of these claims.

13 The drowning case can be rendered in the same form as follows. It is:
}

(D1) Permissible to not attempt a rescue, but

(D2) Morally better to save one than none, and

(D3) Impermissible to save only one when you could save both. 
save both, then you are obliged to save both'. ${ }^{14}$ BOP violations can thus be generalised to a family of cases, in which claims (C1)-(C3) are plausibly true.

\subsection{Lotteries for indivisible goods}

Cases involving conditional obligations are not the only situations in which plausible violations of BOP arise. For example, many people think that morality sometimes requires the use of lotteries to distribute indivisible goods, such as kidneys (Broome 1990; Diamond 1967). Suppose both A and B are equally good candidates for a kidney transplant, but only one kidney is available. ${ }^{15}$ The following three claims jointly violate BOP:

(L1) the moral value of A receiving the kidney is equal to the moral value of B receiving the kidney (because, say, the welfare gains under each outcome are equal).

(L2) there are moral constraints that apply to how the kidneys are allocated: giving a kidney directly to either A or B is impermissible. It is only permissible to use a fair coin toss to select the recipient.

(L3) the moral value of a randomised act is equal to the expected moral value of its parts (and you think the 'parts' here are simply the act of giving a kidney to $\mathrm{A}$ and giving a kidney to $\mathrm{B}){ }^{16}$

To see why (L1)-(L3) violate BOP, let us assign 1 to the value of getting the kidney and 0 to the value of not getting it. If the moral value of a randomised act is equal to the expected moral value of its parts, then the moral value of the coin flip is $\left(\frac{1}{2} * 1+0\right)+\left(\frac{1}{2} * 0+1\right)$, which is 1 . But the moral value of giving the kidney directly to $\mathrm{A}$ is also 1 , as is the moral value of giving the kidney directly to B. Thus, the moral values of the direct acts and the randomised act are equal, but only the randomised acts are permissible. Because BOP claims permissible acts are strictly morally better than impermissible acts, this result violates воР.

\subsection{The doctrine of double effect}

Finally, some deontologists might also have theoretical qualms about Bop since it appears to imply a commitment to teleological theories, which claim the right ${ }^{17}$ depends on the good. Teleological theories are incompatible with deontological views that deny the right depends on the good. Strictly speaking, BOP is compatible with the deontological claim that the right is prior to the good. Yet, since it does

\footnotetext{
${ }^{14}$ Both Pummer (2019) and Horton (2017) discuss a similar case, the 'All or Nothing' problem. However their discussions of this problem are concerned with defending particular solutions to the problem and not, as we are, with the defence of a metaprinciple that places constrains on a family of admissible solutions.

15 We thank Martin Peterson for this example.

16 (L3) is a common consequentialist claim, but it is not universally held by consequentialists. See, e.g., Stefánsson (2015) for a different approach.

17 We will use 'right' interchangeably with 'permissible'.
} 
imply that $y$ cannot be impermissible if $y$ is at least as good as $x$ and $x$ is permissible, moral permissibility assessments that comply with BОР will always be coextensive with those of (non-maximising) ${ }^{18}$ teleological theories.

Whether this is problematic for a deontologist depends on whether they think deontology must differ from teleology only in the considerations that it uses to justify permissibility assessments, or whether deontological moral assessments must also, at times differ from teleological assessments. For example, those who think deontological theories entail different permissibility assessments from consequentialism in some of the trolley problems (Thomson 1985) will be troubled by this implication of BOP.

In particular, BOP is incompatible with an interpretation of the doctrine of double effect, which claims "there is a moral constraint on intending evil (such as harm), even when the evil will be a means to a greater good" (Kamm 2007: 21). ${ }^{19}$ This doctrine is often used to explain non-teleological permissibility assessments in the trolley problem. So, although воР is not directly incompatible with deontology, it is incompatible with permissibility assessments that differ from teleological permissibility assessments, such as those that follow from the doctrine of double effect. Deontologists probably have the strongest theoretical reasons to resist вор. However, the kidney case shows that you also do not need to depart too far from canonical consequentialist views to violate воР.

To reiterate, our purpose in this paper is not to identify which of, e.g., (E1)-(E3) are true. Rather it is to point out that if you accept Bop, then you must reject one of the claims that conflict with вор. And, since we have shown that the weak classical view and reasons monotonicity of permissibility jointly entail BOP, it also follows that if you accept both conditions you cannot endorse the set of BOP-violating claims. We turn now to the evaluation of these two antecedent claims, beginning with the weak classical view.

\section{Assessing the weak classical view}

The weak classical view we outlined above maintains there is a moral reason to perform an act insofar as, and to the degree that, it is morally good. Thus, the weak classical view is false if there are acts that one has a moral reason to perform that are

\footnotetext{
18 Since воP allows that some permissible acts may be morally better than others, it does not imply a commitment to theories like utilitarianism, though it is compatible with them.

19 Like the other example cases, the doctrine of double effect can be made compatible with Bop. One might claim that there there is a side constraint on intending evil, even when it produces consequences that are more good while denying that the act that would produce these consequences is all things considered morally better. The difference in the interpretations depends on how 'greater good' is to be interpreted. Those who would understand 'greater good' in the doctrine as all things considered moral goodness violate воP. There is, however, something unnatural about the way the doctrine of double effect is expressed when one adopts the BOP respecting interpretation: why highlight the pro tanto goodness of the impermissible act if you think it is all things considered morally worse? The Bop violating, all things considered goodness reading seems most plausible. For example, Faraci writes that in situations like Thomson's (1985) surgeon case, "the deontologist's position is that killing the one to save the five is impermissible, despite the fact that it would generate an all-things-considered more valuable outcome" (2019: 175).
} 
not morally good in any respect (even comparably), or if the moral value of an act does not provide any moral reason for its performance. In what follows we assess whether either of these ways the weak classical view could be false is plausible. First we consider three ways moral goodness might be unnecessary for moral reasons. Then we consider one way that it might be insufficient. Although some of these objections will turn out to be misunderstandings, discussing them helps to clarify the weak classical view.

\subsection{Badness and reasons}

In his defence of the strong classical view Raz notes that you might think badmaking features can provide reasons, since agents sometimes "intentionally do what they take to be bad because, as they see it, it is bad" (Raz 1999: 24). For example, "that an action hurts another makes it an intelligible object of choice [since] a desire to hurt, and to watch the other being hurt, exercises great appeal for many people" or again, that an action "will break all the norms, also makes it an intelligible object of choice...we know that often people do what they do precisely because it is the wrong thing to do" (Raz 1999: 24-25). The bad-making features objection claims there is a distinction between those features that make an action an intelligible choice and those that make it a good choice. And if bad-making features can make actions intelligible choices, perhaps they can provide reasons.

Now, prima facie, these are forceful objections to the connection between reasons and goodness in the strong version of the classical view. Although Raz himself offers a compelling rebuttal, we will not focus on his response here because the bad-making features objection is clearly not an objection to the weak classical view. Even if features like an action's being wrong or hurtful are capable of providing reasons tout court, they do not provide moral reasons for action. Perhaps one's wish to do the wrong thing because it is wrong can provide a reason that explains an action. But surely this negatively valued feature does not provide a moral reason for the action (though it might make another action comparatively good, and so, provide a reason to perform a different act). Since the weak classical view concerns the relationship between moral reasons and moral goodness, it appears unlikely any appeal to bad-making features can succeed.

\subsection{Moral neutrality and reasons}

You might instead think that there can be moral reasons to perform acts which have neither good nor bad features. Surely there are many acts that are morally neutralgetting a coffee, deciding to read one article in a magazine rather than another-and yet, there also seem to be reasons to perform such acts.

However, the force of this objection depends on the conflation of neutrally valued and non-valued acts. To say that an act, like getting a cup of coffee, is neutrally valued is to say that the features of this act are equal in moral value to the features of a comparative act. (Usually the comparison is to the status quo, but acts may also be compared to other available options.) We might say that getting a coffee is morally neutral when you have no stronger moral reason to get the coffee 
than to not get the coffee. There are certainly many cases in which acts are neutrally valued. It is true, of course, that when the value of performing act $x$ is equal to the value of performing act $y$, the agent has no greater reason to do $x$ than she has to do $y$. But it does not follow from the fact that $x$ is valued equally to $y$ that she does not have any reason to perform one of the actions. She simply has no stronger reason to $x$ than she does to $y$. Neutrally valued acts pose no threat to the weak classical view, since the reasons for the act the agent performs are still provided by its good-making features.

\subsection{Rightness and reasons}

A much more plausible objection comes from the claim that rightness-not moral goodness-goes hand in hand with moral reasons. Or, more accurately, the claim that when it is impermissible to not act we have a moral reason to act.

Now, note that it is not enough to posit a source of moral reasons that differs from moral goodness if you want to challenge the claim that there can be moral reasons without moral goodness. You must also show that those acts that rightness-based considerations give you a reason to perform are not also morally good. Suppose right-making features are the common source of moral reasons and moral goodness. If rightness is the common source of both reasons and moral goodness, then all acts we have moral reason to perform (because they stem from rightness) will still be morally good (because they also stem from rightness). Consequently, the necessity claim will not be refuted. Thus, a rightness-based objection to the weak classical view must show not only that (1) rightness can be the source of moral reasons, but also (2) some acts that rightness-based considerations provide us with moral reasons to perform are not morally good in any respect. How plausible are these two claims?

First consider (1). Since permissibility is a modal concept that has only two possible values, if moral reasons are a function of permissibility, then moral reasons can also only take one of two values. We would either have a moral reason to perform an action or we would not. The idea that we either have a moral reason, or we do not makes sense if, by 'moral reason' we mean something like 'strongest aggregate reason'. Suppose you could either help a friend move house when you promised to do so, or skip out to watch television with your partner. There might be pro tanto moral reasons to do both, but since the promise to your friend weighs more than (or is lexically prior to) the moral considerations supporting watching television, you have no all things considered moral reason to watch television. Since we do sometimes use 'reasons' to denote what one has all things considered reason to do there is precedent for this modal use of the term.

However, the weak classical view understands reasons differently, as considerations that come in varying degrees. It is a claim not about what we have all things considered moral reasons to do, but about the association of 'smaller', pro tanto moral reasons with moral goodness. Furthermore, note the above motivation of reasons as a modal concept acknowledges the existence of pro tanto reasons. Nevertheless, you might think that this is precisely where the weak view goes wrong: since reasons $d o$ stem from rightness-based considerations, they cannot be the kind of thing that comes in degrees. This is a sort of theoretical stalemate, where 
the defender's modus ponens is the critic's modus tollens. It seems safe to say that the view that moral reasons come in degrees enjoys a broader consensus. It also allows for more nuanced expressions of the way moral reasons relate to actions, for example, by capturing the idea that moral reasons can pull agents in different directions. Nevertheless, we admit there is nothing incoherent about the critic's claim that moral reasons are modal and depend on rightness-based considerations.

Now consider (2), the claim that some acts that we have rightness-based moral reasons to perform are not morally good. One way to motivate this second claim is via the Kantian notion of moral worth. ${ }^{20}$ Kant (1993) claims that the only thing of intrinsic value is a good will (G393-395); which can be illustrated via the concept of duty (G397); and that only actions done from duty have moral worth (G398). Actions done from duty are a subset of permissible actions-they are permissible actions that are performed out of respect for the [moral] law (G400). If moral goodness is construed as Kantian moral worth, then not all permissible acts are morally good. But if an act's permissibility is what provides a moral reason for performing the act, then there can be acts that we have a moral reason to perform that are nevertheless not morally worthy, and thus, not morally good.

Note, however, that if you equate moral goodness with Kantian moral worth (which, to be clear, may not have been Kant's own position ${ }^{21}$ ), you incur a significant expressive cost. If actions are morally good only if they are done from duty, then your theory can no longer capture the ordinary claims that murder is morally worse than theft, since the concept of moral goodness, so understood, applies to neither act. Your theory also does not always imply that charity is morally better than getting a cup of coffee, because here too we need to know which, if either, permissible act is done from duty. Furthermore, the doctrine of double effect's claim that there is a moral constraint on intending evil when the evil will be a means to a greater good implies that there can be morally good, but impermissible acts. If moral goodness is construed as Kantian moral worth, the doctrine's claim would not make sense. Those wishing to reject BOP to save the doctrine of double effect cannot use Kantian moral worth to motivate (2).

These problems do not undermine Kantian moral worth per se. It is reasonable to think that there is something morally distinctive about acts that are done from duty. What they show is that if moral goodness is construed as moral worth-that is, if Kant's views about moral worth are applied to moral goodness in a defence of (2) then many central uses of the concept of moral goodness cannot be preserved.

There is a second, and more serious problem for the strategy of using Kantian moral worth to show there can be moral reasons without moral goodness. If you want to falsify вор, it is not enough to show that the necessity claim in the weak classical view is false. As we show in "Appendix 2", воР also follows from the weaker claim that moral goodness is sufficient for moral reasons (when conjoined with reasons monotonicity). The problem for the moral worth approach here is that

\footnotetext{
${ }^{20}$ We do not wish to take a position on how Kant's views should be interpreted, nor do we claim this defence of (2) is itself a Kantian position. Rather, we show how one possible interpretation of Kantian moral worth can motivate claim (2).

${ }^{21}$ We thank an anonymous referee for pressing us to clarify this point.
} 
it guarantees the sufficiency side of the weak classical view is true. If actions are morally worthy only if they are done from duty, and you have a moral reason for an action only if duty requires its performance, then morally worthy (good) acts are a subset of acts for which you have a moral reason. Therefore, there can never be moral goodness without moral reason. Since the moral worth approach guarantees the sufficiency side of the weak classical view is true, and вор also follows from the sufficiency claim (and reasons monotonicity), then the moral worth approach actually ensures that воР is true. A more promising objection to the weak classical view is to attack the sufficiency claim, which can be done without construing moral goodness as moral worth. We now consider this attack on the sufficiency claim.

\subsection{Goodness without reasons}

If you think that rightness-based considerations are the source of moral reasons, you can retain a broader understanding of moral goodness while still resisting the weak classical view by arguing that acts can have good-making features without these features providing moral reasons for their performance. In this case, the sufficiency claim in the weak classical view would be false. This approach has the added advantage of allowing you to respect the doctrine of double effect's implication that acts can be morally valuable, at least to some degree, without being morally permissible.

You might motivate this claim by claiming that moral reasons are understood subjectively, as those that are capable of explaining why an agent acted as she did. For example, if Bob is about to inadvertently step in front of a moving car, it seems it would be morally good for Alice to stop him, and that there is a moral reason for her to intervene. But if Alice is unaware Bob is about to step into the street, she has no subjective moral reason to stop him. Thus, even though it would be morally good to stop Bob, Alice has no (subjective) reason to do so. As Raz puts it, "when we explain actions by the reasons for which they were undertaken the focus is on the agents' beliefs that they had such and such reasons, beliefs which may be false" (1999: 24). Perhaps, then, moral goodness is insufficient for the presence of subjective moral reasons, since agents are often mistaken or ignorant about what is good, or about what they have objective reasons to do.

While natural, the subjective reading is mistaken. Both the weak and strong classical views are about the nature of the things that agents acting on subjective reasons take themselves to have. These are objective reasons. What the (weak) view says is that these things have to be (morally) good in some respect. And it argues for this as follows: when we think of something as a reason, we can only do so if we think of it as good in some respect. Hence, our very concept of a reason, i.e., of the things we take ourselves to have when we act for reasons, and so objective reasons, is the concept of something that is good in some respect. The argument for the classical view draws out what objective reasons have to be like, if they are to be the things that people take themselves to have, when they act for (subjective) reasons. It argues from the beliefs of agents relevant for intentional explanation to features of the things they have beliefs about, i.e., what such things have to be like for those beliefs to provide the kind of explanation that intentional explanation provides. 
Since the weak classical view is about objective moral reasons, the subjective objection fails.

Perhaps you think there is another way to oppose the sufficiency portion of the weak classical view. Regardless of how compelling your argument is, it will not vindicate many of the counterexamples to BOP. Suppose the weak classical view's sufficiency claim is false and only the necessity claim is retained. Then, as we prove in "Appendix 3", the conjunction of this (even weaker) version of the weak classical view and reasons monotonicity of permissibility (3) still implies that all permissible acts are better than or as good as impermissible acts. This, in turn, implies that no impermissible acts can be morally better than permissible acts. This weaker result is compatible with the kidney case. However, it still conflicts with the counterexamples to BOP based on the doctrine of double effect and conditional obligations. If you wish to reject воР because of your intuitions about these examples, you cannot merely reject the sufficiency portion of the weak classical view.

In summary, if you want to defend the existence of conditional obligations of the kind we outline in Sect. 3, or you want to grant that it is all things considered better to save the many while violating the rights of the one, but you deny that violating these rights is permissible, then you must show that moral reasons for action are neither necessary nor sufficient for moral value.

Yet, as we argued in Sect. 4.3, the most plausible argument against the necessity of moral reasons for moral goodness also establishes that moral reasons are sufficient for moral goodness. Problematically for BOP deniers, this sufficiency claim must be false in order to vindicate the core counterexamples to BоР.

The takeaway is that while there are many ways to technically undermine the connection between moral reasons and moral goodness expressed in the weak classical view, none of the most plausible approaches depart far enough from вор to vindicate the cases that motivate the intuitions that the condition is false. We now consider the prospects for rejecting the second condition, reasons monotonicity of permissibility.

\section{Assessing reasons monotonicity of permissibility}

To begin with, note that you can endorse ethical theories like those used to oppose the weak classical view without rejecting reasons monotonicity of permissibility. As we noted, the most plausible opposition to the weak classical view is an approach that grounds moral reasons in the rightness of an act and not in goodness. However, this view that rightness-based considerations are the source of moral reasons supports the second condition: reasons monotonicity of permissibility. This view that there is a moral reason to perform an act only when it is impermissible to not perform that act (and you think that $\neg \mathrm{P} \neg x \rightarrow \mathrm{Px}$ ), implies that any act that there is a moral reason to perform will be permissible. ${ }^{22}$ So, insofar as there is a moral reason

${ }^{22}$ Note that it does not follow that there is a moral reason to perform any permissible act. 
to perform act $y$, it is permissible. Thus, the monotonicity condition trivially follows from the claim that permissibility is the source of moral reasons.

With these remarks out of the way, we now turn to the central question of this section: How plausible is the monotonicity condition? To answer this, consider first what must be the case if the condition is false. If the condition is false, then there are some acts that are impermissible, but for which there are stronger moral reasons to perform than some permissible acts. Now, prima facie, this implication seems to conflict with the roles these deontic concepts play in answering questions about what to do. To find that action $y$ is impermissible, but $x$ is permissible, is clearly to find that one ought to do the second, but not the first act (provided these are your only two options). It is hard to make sense of this however, if the impermissible act turns out to be the one supported more strongly by the moral reasons.

You might try to motivate an objection to the monotonicity condition by appealing to broader considerations than moral reasons. You could argue that if you have stronger all things considered reasons to perform the impermissible act (despite having stronger moral reasons to perform the permissible act), then you ought to perform the impermissible act. However, this argument equivocates between moral and all things considered 'oughts'. The monotonicity condition, like вOP, is restricted to the moral domain and is silent about the relationship between prudential, moral, and all things considered reasons for action. The fact that you have stronger all things considered reasons for performing a morally impermissible act, does not show that you do not have stronger moral reasons to perform the permissible act.

The monotonicity condition can be false only if there are considerations other than moral reasons that determine what we ought morally to do. But this is just what reasons are-those considerations that serve the function of explaining and guiding what we ought to do are called reasons. And regardless of what you think grounds reasons-whether you think they are grounded in rightness-based considerations and are modal in nature, or that they are grounded in good-making features and are scalar, or that reasons are fundamental and ground goodness, or that they are grounded by something else entirely - there seems to be no strong argument against the claim that role they play in determining what we ought morally to do is, at least minimally consistent with reasons monotonicity of permissibility.

\section{Conclusion}

Suppose that you still feel the pull of the drowning case. You think you are not obliged to save the swimmers, saving one swimmer is better than none, but if you put out to save the swimmers, it is impermissible to save just one. Clearly, these three claims entail that there are some impermissible acts that are morally better than permissible acts, in violation of BOP. Yet many people also intuitively believe that BOP is true. As we noted in the beginning of the paper, without deeper arguments that could justify or explain the truth of BOP we are simply left with conflicting intuitions. Our primary aim in this paper was to identify theoretical claims that could be used to support or criticise воР that went beyond mere 
platitudes. We did so in Sect. 2 by identifying two antecedent claims that jointly entail вор. In Sect. 3 we identified a number of cases that elicit Bop-violating intuitions, thus demonstrating the importance of assessing the truth of the two antecedent claims.

Our secondary aim was to assess the truth of these antecedent claims. In Sect. 4 we showed that the most plausible way to reject the necessity portion of the weak classical view also entailed the truth of the sufficiency portion of that claim. And as we show in "Appendix 2", the sufficiency side of the weak classical view also (with reasons monotonicity) entails BOP. Furthermore, even if the sufficiency portion of the weak classical view is false, the necessity side of the view (with reasons monotonicity) entails a weak version BOP that is still incompatible with many of the cases that motivate an opposition to воР. That is, in order to vindicate intuitions about those cases that violate BOP, moral goodness must be neither necessary nor sufficient for moral reasons.

We discussed the plausibility of reasons monotonicity of permissibility in Sect. 5. There we argued the condition is true, unless considerations other than moral reasons can determine what we ought morally to do. Yet, since moral reasons are defined as those things, whatever they are, that tell us what we ought to do, we concluded that reasons monotonicity of permissibility is true.

The truth of reasons monotonicity of permissibility and the weak classical view provide deeper reasons for endorsing BOP and rejecting the BOP violating verdicts in the counterexample cases. Nevertheless, we confess that we still feel the pull of the counterexamples, especially cases involving conditional obligations. We have not discussed which of the general claims $(\mathrm{C} 1)-(\mathrm{C} 3)$ is likely to be false in each of the cses, nor have we provided an error theory explaining why the claims should be so compelling in the first place. We believe these are both fruitful areas for further analysis.

Acknowledgements This paper was presented at the University of Hamburg's Normative Theory Group Workshop. We thank those present for helpful comments. We also thank Jason Alexander, Vuko Andrić, Matthew Braham, Chlump Chatkupt, Fabian Gruben, Akshath Jitendranath, Roland Luttens, Olivier Roy, Geoff Sayre-McCord, Orri Stefánsson, Martin van Hees, Martin Peterson, Jan-Willem van der Rijt, and Peter Vallentyne for comments and suggestions. Special thanks to Marina Uzunova for her help with the proofs. Funding was provided by Nederlandse Organisatie voor Wetenschappelijk Onderzoek (NL) (Grant No. 275-20-063).

Open Access This article is distributed under the terms of the Creative Commons Attribution 4.0 International License (http://creativecommons.org/licenses/by/4.0/), which permits unrestricted use, distribution, and reproduction in any medium, provided you give appropriate credit to the original author(s) and the source, provide a link to the Creative Commons license, and indicate if changes were made. 


\section{Appendix}

\section{Entailment proof}

The weak classical view (2) and reasons monotonicity of permissibility (3) jointly entail вор (1). That is:

$$
\begin{aligned}
& {\left[\forall x, y \in X: x \succcurlyeq_{r} y \leftrightarrow x \succcurlyeq_{m} y\right] \wedge\left[\forall A \in Z, \forall x, y \in A:\left(\mathrm{P} x \wedge\left(y \succcurlyeq_{r} x\right)\right) \rightarrow \mathrm{P} y\right]} \\
& \quad \Rightarrow\left[\forall A \in Z, \forall x, y \in A:(\mathrm{P} x \wedge \neg \mathrm{P} y) \rightarrow x \succ_{m} \quad y\right]
\end{aligned}
$$

To prove (4) we first prove the following lemma:

$$
\forall A \in Z, \forall x, y \in A:\left[\left(\mathrm{P} x \wedge\left(y \succcurlyeq_{r} x\right)\right) \rightarrow \mathrm{P} y\right] \rightarrow\left[(\mathrm{P} x \wedge \neg \mathrm{P} y) \rightarrow x \succ_{r} y\right]
$$

Proof of Lemma Assume $\left(\mathrm{P} x \wedge\left(y \succcurlyeq_{r} x\right)\right) \rightarrow \mathrm{P} y$. Take $\mathrm{P} x$ and $\neg \mathrm{P} y$. To show: $x \succ_{r} y$.

The contrapositive of $\left(\mathrm{P} x \wedge\left(y \succcurlyeq_{r} x\right)\right) \rightarrow \mathrm{P} y$ is:

$\neg \mathrm{P} y \rightarrow \neg\left(\mathrm{P} x \wedge\left(y \succcurlyeq_{r} x\right)\right)$, equivalent to

$\neg \mathrm{P} y \rightarrow\left(\neg \mathrm{P} x \vee \neg\left(y \succcurlyeq_{r} x\right)\right)$, equivalent to

$\neg \mathrm{P} y \rightarrow\left(\neg \mathrm{P} x \vee x \succ_{r} y\right)$, by completeness.

From $\neg \mathrm{P} y$ and $\neg \mathrm{P} y \rightarrow\left(\neg \mathrm{P} x \vee x \succ_{r} \quad y\right)$, it follows that either $\neg \mathrm{P} x$ or $x \succ_{r} \quad y$. Since we have $\mathrm{P} x$, it follows that $x \succ_{r} y$.

Proof of (4) Assume (2) and (3) hold. To show: (1) holds.

From (3) (by assumption) and lemma (5) we have $(\mathrm{P} x \wedge \neg \mathrm{P} y) \rightarrow x \succ_{r} \quad y$. By (2) and completeness, this is equivalent to $(\mathrm{P} x \wedge \neg \mathrm{P} y) \rightarrow x \succ_{m} \quad y$, which is (1).

\section{BOP via the sufficiency of the weak classical view}

Suppose you abandon the necessity claim in the weak classical view, so that

$$
\forall x, y \in X: \quad x \succcurlyeq_{m} y \rightarrow x \succcurlyeq_{r} y
$$

Then, (6) and (3) entail вор (1).

Proof Assume that (6) and (3) hold. To show: воP (1) holds. That is to say, assume that $P x$ and $\neg P y$ hold. To show: $x \succ_{m} \quad y$.

By reasons monotonicity (3) and lemma (5), we have $(\mathrm{P} x \wedge \neg \mathrm{P} y) \rightarrow x \succ_{r} \quad y$. From $P x \wedge \neg P y$ (by assumption) and $(\mathrm{P} x \wedge \neg \mathrm{P} y) \rightarrow x \succ_{r} \quad y$, we have $x \succ_{r} y$.

By definition, $x \succ_{r} y$ is equivalent to $x \succcurlyeq_{r} y$ and $\neg\left(y \succcurlyeq_{r} x\right)$.

By (6), we have $y \succcurlyeq_{m} x \rightarrow y \succcurlyeq_{r} x$.

The contrapositive of which is $\neg\left(y \succcurlyeq_{r} x\right) \rightarrow \neg\left(y \succcurlyeq_{m} x\right)$.

Thus, using $\neg\left(y \succcurlyeq_{r} x\right)$, we have $\neg\left(y \succcurlyeq_{m} x\right)$.

By completeness of $\succcurlyeq_{m}$, we must have $x \succcurlyeq_{m} y$.

From $\neg\left(y \succcurlyeq_{m} x\right)$ and $x \succcurlyeq_{m} y$, it follows by definition that $x \succ_{m} y$. 


\section{Weakening the weak classical view}

Suppose you abandon the sufficiency claim in the weak classical view, so that

$$
\forall x, y \in X: \quad x \succcurlyeq_{r} y \rightarrow x \succcurlyeq_{m} y
$$

Then, (7) and (3) entail the following weak betterness of permissibility claim:

$$
\forall A \in Z, \forall x, y \in A: \quad(P x \wedge \neg P y) \rightarrow x \succcurlyeq_{m} y
$$

Proof Assume that (7) and (3) hold. To show: (8) holds. That is to say, assume that $P x$ and $\neg P y$ hold. To show: $x \succcurlyeq_{m} y$.

From (3) and lemma (5), we have $\left((\mathrm{P} x \wedge \neg \mathrm{P} y) \rightarrow x \succ_{r} \quad y\right.$.

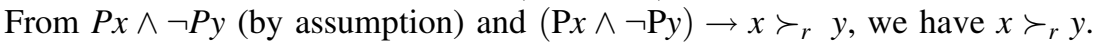

By definition, $x \succ_{r} y$ is equivalent to $x \succcurlyeq_{r} y$ and $\neg\left(y \succcurlyeq_{r} x\right)$.

From $x \succcurlyeq_{r} y$ and (7), we have $x \succcurlyeq_{m} y$.

\section{References}

Anscombe, G. (1957). Intention. Oxford: Basil Blackwell.

Aristotle. (1999). [349 BC] Nicomachean ethics. 2nd edn. (T. Irwin, Trans.). Indianapolis: Hackett.

Broome, J. (1990). Fairness. Proceedings of the Aristotelian Society, 91, 87-101.

Broome, J. (1991). Weighing Goods. Oxford: Blackwell.

Chang, R. (2002). The possibility of parity. Ethics, 112, 659-688.

Chang, R. (1997). Incommensurability, incomparability, and practical reason. Cambridge: Harvard University Press.

Davidson, D. (1963). Actions, reasons, and causes. The Journal of Philosophy, 60(23), 685-700.

Davidson, D. (1980). How is weakness of the will possible? Essays on actions and events (pp. 21-42). Oxford: Clarendon Press.

Diamond, P. (1967). Cardinal welfare, individualistic ethics, and interpersonal comparison of utility: Comment. Journal of Political Economy, 75(5), 765-766.

Faraci, D. (2019). Wage exploitation and the nonworseness claim: Allowing the wrong, to do more good. Business Ethics Quarterly, 29(2), 169-188.

Ferguson, B. (2016). The paradox of exploitation. Erkenntnis, 81(5), 951-972.

Griffin, J. (1986). Well-being: Its meaning, measurement and importance. Oxford: Clarendon Press.

Horton, J. (2017). The all or nothing problem. The Journal of Philosophy, 64(2), 94-104.

Kamm, F. (2007). Intricate ethics: Rights, responsibilities, and permissible harm. Oxford: OUP.

Kant, I. (1993) [1785]. Grounding for the Metaphysics of Morals (3rd edn). Indianapolis: Hackett.

Peterson, M. (2013). The dimensions of consequentialism: Ethics, equality and risk. Cambridge: Cambridge University Press.

Pummer, T. (2019). All or nothing, but if not all, next best or nothing, Journal of Philosophy, 116(5), 278-291 (forthcoming).

Raz, J. (1999). Engaging reason. Oxford: Oxford University Press.

Raz, J. (1986). The morality of freedom. Oxford: Clarendon Press.

Sartre, J. (2007). Existentialism is a humanism. New Haven: Yale University Press.

Scanlon, T. (1998). What we owe to each other. Cambridge, MA: Harvard University Press.

Smith, M. (2009). Two kinds of consequentialism. Philosophical Issues, 19, 257-272.

Sobel, D. (2013). Self-ownership and the conflation problem. In M. Timmons (Ed.), Oxford studies in normative ethics (Vol. 3, pp. 98-122). Oxford: Oxford University Press.

Stefánsson, H. (2015). Fair chance and modal consequentialism. Economics and Philosophy, 31(3), 371-395.

Styron, W. (1980). Sophie's choice. New York: Bantam Books. 
Temkin, L. (2012). Rethinking the good: Moral ideals and the nature of practical reasoning. Oxford: Oxford University Press.

Thomson, J. (1985). The trolley problem. The Yale Law Journal, 94, 1395-1415.

Vallentyne, P. (1993). The connection between prudential and moral goodness. Journal of Social Philosophy, 24, 105-28.

Voorhoeve, A. (2013). Vaulting Intuition: Temkin's critique of transitivity. Economics and Philosophy, $29,409-25$.

Wertheimer, A. (1996). Exploitation. Princeton: Princeton University Press.

Zwolinski, M. (2007). Sweatshops, choice, and exploitation. Business Ethics Quarterly, 17(4), 689-727.

Publisher's Note Springer Nature remains neutral with regard to jurisdictional claims in published maps and institutional affiliations. 